\title{
La muerte de Alejandro Sawa y la duda de Ernesto Bark: una supuesta catalepsia tres veces novelada
}

\author{
Rocío Santiago Nogales ${ }^{1}$ \\ UNED
}

Resumen: Poco se sabe del verdadero velatorio de Alejandro Sawa; sin embargo, su figura y sus anécdotas han trascendido tanto que ya no solo su persona, sino su velatorio ha sido recreado hasta tres veces en la literatura: en El árbol de la ciencia de Pío Baroja, en Luces de Bohemia de Valle-Inclán y en Las máscaras del héroe de Juan Manuel de Prada. Las tres obras están íntimamente conectadas entre sí y traspasan el delgado límite entre realidad y ficción, de ahí que el comparatismo tenga mucho que decir en este análisis y en la aparición de ciertos personajes, como Ernesto Bark, el verdadero causante de sembrar la duda sobre la efectiva muerte del bohemio, quien sostuvo hasta el final de su vida que su amigo se suicidó.

Palabras clave: Alejandro Sawa, velatorio, El árbol de la ciencia, Luces de Bohemia, Las máscaras del héroe, Ernesto Bark.

\section{Alejandro Sawa's death and Ernesto Bark's doubt: a supposed catalepsy that was fictionalized three times}

Abstract: Alejandro Sawa's death is not known with details. However, bohemian life and many Sawa's adventures are so attractive that not only his life, but also his death has been told by our best authors. His funeral wake has been recreated three times in Literature: The Tree of Science of Pio Baroja, Bohemian Lights of Valle-Inclán and The Masks of Hero of Juan Manuel de Prada. These works are intimately connected to each other and cross the boundary between reality and fiction. In this comparative study we want to discover what is true and what is false and explain why some characters appear in books, such as Ernesto Bark, who said not only that Sawa hadn't died and it was a catalepsy case, but also that Sawa commited suicide.

Key words: Alejandro Sawa, funeral wake, The Science Tree, Bohemian Lights, The Masks of Hero, Ernesto Bark.

1 Personal Investigador en Formación en la UNED. 


\section{INTRODUCCIÓN}

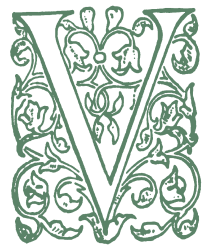

amos a comenzar haciendo una afirmación bastante rotunda que debe servirnos de guía a lo largo de estas líneas: poco se sabe del auténtico velatorio de Alejandro Sawa, el escritor bohemio nacido en Sevilla en 1862 y fallecido en Madrid en 1909. Es más, Alonso Zamora Vicente, en su obra Asedio a Luces de Bohemia, dijo: «Nadie sabe cómo fue la escena auténtica del entierro» (Zamora Vicente, 1967: 32). Siendo así, todo lo que se pueda decir de su muerte estará cargado de grandes dosis de suposición. Si a esto le sumamos el halo de leyenda que siempre flotó sobre la figura de Sawa y el hecho constatado de que sus anécdotas, tantas veces exageradas y otras tantas inventadas, trascendieron mucho más que él mismo como literato, y que los lectores nos dejamos seducir por El árbol de la ciencia (1911), Luces de Bohemia (1924)² o Las máscaras del héroe (1996), nos movemos en la necesidad de discernir entre qué es realidad, qué es ficción y dónde está el límite entre ambas $^{3}$.

Tras el pertinente análisis comparativo de las tres obras entre $\mathrm{si}^{4} \mathrm{y}$ de estas con la realidad, nos detendremos en un pasaje concreto: la catalepsia de Alejandro Sawa, la cual aparece en las tres ficciones. Hasta ahora, se ha creído que el artífice de semejante revuelo fue Valle-Inclán (1866-1936); sin embargo, hemos conseguido demostrar que vino de la mano de Ernesto Bark (1858-1922). Este será un dato fundamental que arrojará mucha luz al debate entablado entre los críticos, pues no solo consigue explicar por qué los escritores deciden novelar los hechos de un modo concreto, sino que ampliará las vías de investigación por un camino que jamás ha sido tratado: es posible que Alejandro Sawa se suicidase.

\footnotetext{
2 Si bien la edición definitiva es de 1924, Valle-Inclán fue publicando Luces de Bohemia por entregas durante varias semanas, desde el 31 de julio al 23 de octubre de 1920, en la revista España. En esa primera versión aún faltaban tres escenas por incluir.

3 Entenderemos por realidad los hechos constatados que han ocurrido y son comprobables desde un punto de vista histórico y por ficción todo aquello que pertenece a la literatura y ha sido novelado o es pura invención.

4 También haremos un repaso del estado de la cuestión de la relación entre las obras.
} 


\section{EL VELATORIO DE ALEJANDRO SAWA}

El primer velatorio de Sawa es, obviamente, el suyo propio. A la una menos cuarto de la madrugada del 3 de marzo de 1909, fallecía, a punto de cumplir los cuarenta y siete años, en un humilde piso de la calle del Conde Duque de Madrid, en el número $3^{5}$, a causa de una encefalitis que le hizo perder la cabeza el 18 de febrero de ese mismo año y agonizar durante varios días (Iglesias Hermida, 1909: 91). La doctora Amelina Correa Ramón explica detenidamente en la biografía de Alejandro Sawa que la encefalitis, en su fase aguda, produce delirios durante más de una semana, dolores de cabeza, confusiones, alteraciones en la personalidad y desemboca en la muerte (Correa Ramón, 2008: 257).

En la más absoluta pobreza dejaba una mujer y una hija de dieciséis años (Jeanne Poirier y Helena Rosa Sawa, respectivamente). El velatorio se hizo en el propio domicilio y, al día siguiente, fue enterrado en el Cementerio de la Almudena en paupérrimas condiciones. Pocos fueron los amigos que lo velaron y asistieron a su entierro ${ }^{6}$, pero entre esos nombres debemos destacar a Ramón del Valle-Inclán, Ernesto Bark y Nicasio Hernández Luquero (18841975), por los motivos que vamos a desarrollar a continuación.

Valle-Inclán, además de ser el autor de Luces de Bohemia, cuyo protagonista, Max Estrella, está inspirado en la figura de Alejandro Sawa, merece especial atención por recriminar a Rubén Darío (1867-1916) su ausencia en el velatorio del bohemio. Como prueba de este reproche, existe una carta ${ }^{7}$ que envió el gallego al nicaragüense con el fin de informarle de que él mismo venía de dicho lugar. Sin embargo, en esta misiva no se aportan datos sobre el desarrollo de los acontecimientos, tan solo dice que Sawa «tuvo el final de un rey de tragedia: loco, ciego y furioso» (Valle-Inclán, 1909) ${ }^{8}$.

\footnotetext{
5 Hoy en día, tras la nueva numeración de las calles, se corresponde con el número 7, donde El Círculo de Bellas Artes colocó en 2003 una placa conmemorativa.

6 Esta lista se reconstruye en Correa Ramón (2008: 260), remitiendo a una copia de una carta enviada por el fallecido días antes a Jacinto Benavente, al dorso de la cual alguien anotó los nombres de los presentes en el domicilio durante el velatorio. Por otro lado, existe otra lista en la que figuran menos nombres, en González Martel, (2006: 80). Asimismo, El País, en su edición del 5 de marzo de 1909, también publicaba en portada la lista de asistentes, en el artículo «Entierro de Alejandro Sawa».

7 «Mítica carta en la que nuestro bohemio queda elevado a la categoría de quien será el héroe del primer esperpento valleinclaniano» (Ena, 2012-2013: 40).

8 Esta carta se encuentra en el Archivo Rubén Darío, Universidad Complutense de Madrid, doc. 2036. La carta no tiene fecha, pero es obvio que data del 3 de marzo de 1909, día del fallecimiento de Sawa.
} 
Por otro lado, a pesar del gran eco que se hicieron los periódicos de la noticia del fallecimiento, lo cierto es que se limitaron a elogiar las virtudes literarias de Alejandro Sawa y a dar información sobre el lugar y la hora del entierro, sin rastro alguno de lo que había ocurrido en el pobre piso de la calle del Conde Duque. Tan solo Nicasio Hernández Luquero da testimonio de lo que presenció, pero lo hace con el inconveniente de las contradicciones en sus propios artículos. Tres son las veces que recuerda a Sawa muerto y muchos los años que separan a estos recordatorios: el primer artículo se publicó en El País, el 8 de marzo de 1909; el segundo en el Diario de Ávila ${ }^{9}$, el 2 de marzo de 1967 y el último es del $A B C$, del 22 de mayo de 1974. Puede que la admiración de este poeta y periodista segoviano hacia el bohemio le llevara a exagerar, incluso a distorsionar, sus aportaciones. Es más, tal vez, obnubilado por la desgracia que había acontecido, el propio periodista transmitió más sus percepciones que los hechos reales. Aparte de una breve descripción de aquello que rodeaba al cadáver, afirma que nunca trató con el artista; en cambio, como observa Allen Phillips, en el artículo de 1967 dice haberlo conocido y haber hablado tan solo una vez con él (Phillips, 1976: 27). Otro dato que llama la atención es que ni en el primer texto, ni en el último, hay rastro de un famoso clavo que sobresalía del ataúd y perforó la sien del difunto ${ }^{10}$, sembrando la duda sobre la efectiva muerte, cosa que sí recuerda en 1967.

En 1909, Hernández Luquero tan solo hace referencia, en relación con el velatorio, al aspecto de Sawa, quien estaba envuelto en un sudario blanco y seguía manteniendo una buena apariencia: «[...] en muerte, envuelto en la blancura sencilla de un sudario, triunfal de aspecto [...]» (Hernández Luquero, 1909). En 1967, da más información y nos relata una anécdota, aparentemente y según el testimonio del periodista, protagonizada por Valle-Inclán, quien sembró la duda sobre si estaba vivo o muerto a causa del hilo de sangre que brotó al rozarse con el mencionado clavo. Como consecuencia, tuvieron que buscar un espejo para comprobar que Sawa había fallecido. Esto lo recoge Hernández Luquero en aquel artículo que publicó en el Diario de Ávila: «[...] Pero a Valle-Inclán, siempre extraño y fantástico, se le antojó que Alejandro estaba vivo. Hubo que buscar un espejo, que, ¡cosa natural!,

9 Este artículo fue facilitado por Idelfonso-Manuel Gil a Allen Phillips, como se dice en Phillips, (1976: 27, nota al pie núm. 17).

10 Allen Phillips hace referencia a esta omisión irónicamente: «Hernández Luquero se olvida del hilillo de sangre [...]» (Phillips, 1976: 27). 
no reflejó el aliento del elegante cronista» (Hernández Luquero, 1967) ${ }^{11}$. Y, por último, en 1974, retoma casi idéntico discurso al que tuvo en 1909, añadiendo: "Yo le contemplé muerto en aquel cuarto humilde de la Travesía ${ }^{12}$ del Conde-Duque, bajo un soporte lleno de pipas y el cuadro que, tras un cristal, guardaba un soneto ${ }^{13}$ inédito y autógrafo de Verlaine» (Hernández Luquero, 1974).

Aquí concluye el verdadero velatorio de Alejandro Sawa. A modo de síntesis, estos son los únicos datos que podemos afirmar como verídicos: murió el 3 de marzo de 1909, a la una menos cuarto de la madrugada, ciego y a causa de una encefalitis. El velatorio se hizo en el domicilio familiar, que correspondía con el piso principa ${ }^{14}$ de la calle Conde Duque número 3 de Madrid. Su ataúd era pobre y fue envuelto en un sudario blanco dentro del que mantenía un buen semblante. Al tratarse de un ataúd de tercera, un clavo sobresalía, con tan mala suerte que hirió la sien del difunto, sembrando la duda de si realmente había fallecido; por ello, se comprobó la muerte con un espejo. Pocos fueron los asistentes al velatorio y posterior entierro, pero piadoso el homenaje que se le rendía al bohemio al poner una mesa junto a su féretro con su colección de pipas, un poema y un retrato de Paul Verlaine (18441896) ${ }^{15}$. Asimismo, en el legado familiar se puede comprobar que existe un retrato del fallecido que alguien hizo a carboncillo (Correa Ramón, 2008: 259) y que su viuda cortó un mechón del cabello de su difunto esposo, reliquia que también se ha conservado en dicho legado (Correa Ramón, 2008: 259).

\section{TRES FICCIONES SOBRE SU MUERTE}

\section{La catalepsia de Rafael Villasús}

A partir de este momento, nos adentramos en las tres ficciones a las que ha dado lugar este suceso. Pese al debate que se ha entablado entre los in-

\footnotetext{
11 Recordemos que este artículo es rescatado por Allen Phillips. Este fragmento lo recoge en Phillips, (1976: 31, nota al pie núm. 21).

12 Confunde la Calle del Conde de Duque con la Travesía del Conde Duque, calle perpendicular a aquella.

13 No es un soneto, sino un poema de dieciséis versos: «[...] el poema no era un soneto, sino otra versión del titulado "Féroce", publicado en Le Rêve et l'Idée, mayo-julio de 1895» (Correa Ramón, 1993: 50).

14 Era el piso principal porque así consta en la firma que Alejandro Sawa reflejaba en sus cartas a mano: «Alejandro Sawa, Calle del Conde Duque, 3, principal».

15 Alejandro Sawa conoció a Paul Verlaine en su estancia en París y lo consideraba todo un referente.
} 
vestigadores, este siempre ha ido encaminado a comprobar si las obras posteriores recrean la escena a partir de las anteriores. Falta, por lo tanto, una comparación exhaustiva entre los personajes que aparecen con papel similar, detenerse en qué cambios se introducen y por qué y, lo más importante, si existe una explicación para todo ello basada en los hechos verídicos, sobre todo para el controvertido supuesto de catalepsia.

En primer lugar, aparece Alejandro Sawa en El árbol de la ciencia, enmascarado tras un escritor de dramas llamado Rafael Villasús. Su descripción es bastante satírica, pues Pío Baroja (1872-1956) no simpatizaba con la vida bohemia y, si en el protagonista de la novela, Andrés Hurtado, se refleja a sí mismo haciendo del personaje su alter ego, en Rafael Villasús, un escritor que muere ciego y loco, quiere representar a Sawa; o, lo que es lo mismo, el antagonista a lo que el vasco consideraba una buena forma de vida.

En el Capítulo VIII de la novela, se narra el velatorio del tal Villasús, quien había estado agonizando tres días y tres noches y cuyo cadáver se encontraba tendido en el suelo y estaba rodeado por los amigos del difunto, a quienes Baroja llama no pocas veces desarrapados. El fragmento que más nos interesa es el siguiente:

- Pues reconozca usted el cuerpo, porque creemos que Villasús no está muerto. Esto es un caso de catalepsia. [...] Todos aquellos desarrapados, que debían ser bohemios, amigos de Villasús, habían hecho horrores con el cadáver: le habían quemado los dedos con fósforo para ver si tenía sensibilidad. [...]

En esto entró un viejo de melena blanca y barba también blanca, cojeando, apoyado en un bastón. Venía borracho completamente. Se acercó al cadáver de Villasús, y con una voz melodramática gritó:

- ¡Adiós, Rafael! ¡Tú eras un poeta! ¡Tú eras un genio! ¡Así moriré yo también! ¡En la miseria!, porque soy un bohemio y no venderé nunca mi conciencia. No. (Baroja, 2005: 264 y ss).

Hay que tener en cuenta que Baroja no estaba entre los asistentes al velatorio, de modo que todo lo que refleja en este pasaje es pura invención ${ }^{16}$. El

16 Parte de la crítica sostiene que Baroja se sujetó más a los hechos: «parece que Baroja, sin entrar en tantos detalles, fue más fiel a la realidad» (García Besada, 2001: 62). Sin embargo, no podemos aceptar este tipo de afirmaciones porque, como acabamos de apuntar, Baroja no estuvo presente en el velatorio y 
escritor vasco decidió crear un personaje bohemio y, de este modo, aprovechó para criticar la propia vida bohemia, de la que Alejandro Sawa era representativo. De ahí que el personaje tome los rasgos más significativos de las sonoras circunstancias que rodearon el fallecimiento de Sawa: pobre, ciego y loco. Además, Villasús es totalmente secundario en la novela, al igual que Sawa fue secundario en la vida de Baroja, y viceversa. Dice García Besada que Villasús es solo «un elemento más de aquel ambiente degradado que Baroja nos muestra» (2001:59). Ahora bien, la fugacidad de su aparición no es impedimento para que su descripción sea más hiriente que la de otros personajes:

Y es que, a lo largo de la obra, pero muy especialmente en el caso de Villasús-Sawa, Baroja se cuela entre los insultos, que, si bien se prodigan en la narración con casi todos los personajes, con el pobre Villasús y su familia alcanzan niveles de auténtico desprecio; es la diferencia entre hablar de un personaje más o menos típico, pero inventado, a hablar de alguien a quien se ha conocido, con quien se ha tratado y no digamos si, además, hubo enemistad (García Besada, 2001: 60).

Especial mención merece el asunto de la supuesta catalepsia, no solo porque en la realidad se dudase de la muerte, sino porque la prueba que se hace es la de quemar los dedos con un fósforo. De tal práctica no hay ni rastro en los escasos testimonios que mencionábamos en el epígrafe anterior, pero Baroja decide darle un giro más espantoso que agudiza su crítica contra los desarrapados. Esto sienta un precedente que se va a repetir en las dos obras que nos faltan por comentar. De igual modo, el viejo borracho que entra dando gritos tiene personaje análogo en dichas obras.

\section{La catalepsia de Max Estrella}

A 1924 (o 1920) nos trasladamos para encontrarnos con un pasaje muy similar al anterior en Luces de Bohemia:

Don Latino: ¡Ha muerto el Genio! ¡No llores, hija mía! ¡Ha muerto y no ha muerto!... ¡El Genio es inmortal!... [...] jMurió pobre, como debe morir el Ge-

porque el escritor vasco quiere desprestigiar la bohemia, perdiendo la objetividad con sus descripciones peyorativas. Además, hay que tener en cuenta la intencionalidad de cada escritor, que es lo que le hace contar las cosas de un modo u otro. Analizar este aspecto es uno de los objetivos del presente artículo. 
nio! ¡Max, ya no tienes una palabra para tu perro fiel! ¡Max, hermano mío, si menor en años, mayor en... [...] iTe acuerdas, hermano? ¡Te has muerto de hambre, como yo voy a morir, como moriremos todos los españoles dignos! [...] (Valle-Inclán, 1987: 178 y ss).

Efectivamente, la intervención de Don Latino lamentando la muerte de Max Estrella se asemeja a la del viejo borracho de melenas que se lamenta por la de Villasús ${ }^{17}$. Ambos claman por lo mismo y elevan a la categoría de genio al fallecido. A continuación, se vuelve a hablar de la supuesta catalepsia y se hace la misma prueba del fósforo ardiendo en los dedos para comprobar la defunción:

Basilio Soulinake: ¿Quién certificó la defunción? [...] Y en esa primera impresión me empecino, como dicen los españoles. Madama Collet, tiene usted una gran responsabilidad. ¡Mi amigo Max Estrella no está muerto! Presenta todos los caracteres de un interesante caso de catalepsia. [...]

El cochero: Póngale usted un mixto encendido en el dedo pulgar de la mano. Si se consume hasta el final, está tan fiambre como mi abuelo. ¡Y perdonen ustedes si he faltado!

El cochero fúnebre arrima la fusta a la pared y rasca una cerilla. Acucándose ante el ataúd, desenlaza las manos del muerto y una vuelve por la palma amarillenta. En la yema del pulgar le pone la cerilla luciente, que sigue ardiendo y agonizando (Valle-Inclán, 1987: 184 y ss).

Es indiscutible que Valle-Inclán se recrea en la escena mientras que Baroja pasa de puntillas, por la simple razón de que Luces de Bohemia se centra en Max Estrella, siendo su muerte el punto más álgido de la obra, mientras que El árbol de la ciencia se entrega a Andrés Hurtado, reflejando en Villasús una mera anécdota. Salvando estas diferencias, no hay duda de que el gallego leyó al vasco para partir de las mismas circunstancias, pero haciendo justicia, a su modo, a su difunto amigo. Valle-Inclán aporta datos verídicos porque él sí estuvo en el velatorio, pero eso no quiere decir, ni mucho menos, que busque la exactitud histórica ${ }^{18}$. Sin embargo, a pesar de la gran carga de fic-

\footnotetext{
17 Semejante personaje que irrumpe ebrio no aparece en los testimonios reales y por lo tanto no podemos establecer ninguna correspondencia en la realidad, pero sí observar su reiteración en la ficción.

18 Max Estrella vive acontecimientos político-sociales que sucedieron cuando Alejandro Sawa llevaba más de una década muerto. Asimismo, el personaje presenta la ideología de su propio creador y muchos
} 
ción que intencionadamente presenta Luces de Bohemia, «es cierto que el inmortal Max Estrella valleinclaniano ha evitado que el nombre de Alejandro Sawa permaneciese en un mayor desconocimiento» (Ena, 2012-2013: 39) y ha conseguido eclipsar a Villasús, acentuando su genialidad en detrimento de todas las consideraciones despectivas que arrastraba en la obra barojiana.

La relación entre ambas obras ha sido motivo de debate entre Allen Phillips, Ricardo Senabre, Peter Dunn, Gonzalo Sobejano e Idelfonso-Manuel Gil. El primero trata, en mayor o menor medida, las opiniones de todos los demás ${ }^{19}$. Es así, sometiendo a crítica los estudios, como manifiesta sus propias conclusiones:

Fue Baroja el primero que traslada, en 1911, la realidad de la muerte de Sawa a un capítulo de El árbol de la ciencia [...] Baroja [...] sentía poca simpatía por Alejandro Sawa, y no creo que le preocupara gran cosa su desaparición. Aquella realidad de 1909, por lo demás, era para Baroja seguramente una realidad vivida de manera indirecta o lejana y no un motivo de verdadera compasión [...] Algunos años más tarde también Valle-Inclán se ocupará de la misma circunstancia, pero con mayor extensión por tratarse del protagonista de Luces de bohemia [...] Ambos autores consideran aptos para sus respectivas figuraciones novelescas ciertos hechos reales de la muerte de Sawa, y cada uno a su modo reelabora aquella realidad penosa para aprovecharla en su propia creación artística [...] (Phillips, 1976: 29-30).

Salvando detalles, casi todos los investigadores coinciden en destacar la relación entre las obras, pero moviéndose en un espectro que va desde el plagio hasta una leve relación, aunque García Besada se aparta de esta postura al decir:

Se podría pensar que Valle, al leerla, tomase algunos detalles de la obra de su colega, pero parece más verosímil pensar que o el propio Valle estuvo presente- dada su amistad con el muerto, cosa que no habría ocurrido en el caso de Baroja por razones varias- o que el hecho, como ya dijimos, circulaba por los mentideros de la villa (2001: 64).

de los otros personajes que aparecen, que tienen correspondencia con políticos o escritores, no pudieron convivir. Esto deja de manifiesto que Luces de Bohemia reúne la esencia de una época condensada en dos horas de lectura que abarcan una noche de ficción, de ahí la dificultad de establecer lazos con la realidad. A lo sumo, hablamos de meras coincidencias e inspiraciones: un escritor ciego e intelectualmente superior al vulgo, con una mujer francesa y una hija adolescente, al que retiran una colaboración en un periódico.

19 Dicho debate se trata en Phillips, (1976: 29 y ss.), y en sus respectivas notas al pie. 
Por su parte, Inman Fox, a quien cita Caro Baroja en su edición de El árbol de la ciencia, considera que Valle-Inclán plasma la «escena barojiana en todo su detalle» (Caro Baroja, 2005: 267) ${ }^{20}$, tomando una posición bastante radical.

Podríamos decir que ninguna de las posturas es totalmente verdadera o totalmente falsa. Phillips es, quizás, quien analiza el asunto con más cautela, pero no creemos que sea acertado decir que Baroja traslada «la realidad de la muerte de Sawa a un capítulo» porque, como dice después, esta no fue conocida de cerca por el vasco. Tampoco aceptamos la inexistencia de influencias porque la realidad no se puede tomar como punto de partida y porque son demasiadas las coincidencias entre ambas obras. Por ello, hemos de elaborar una reflexión justificando qué es admisible y qué desestimable de las opiniones de los estudiosos. Para empezar, El árbol de la ciencia y Luces de Bohemia son dos obras totalmente distintas, con intenciones bien diferentes: «Valle trata a Sawa- Max Estrella de manera radicalmente opuesta a Baroja» (García Besada, 2001: 60) y distantes en el tiempo. Si bien Baroja solo pudo saber de las trágicas circunstancias de la muerte de Sawa, Valle-Inclán estuvo presente en el velatorio y en el entierro. Que ambos compartan un episodio no es más que una consecuencia derivada de sus percepciones, por lo que deberíamos aceptar que son los mismos hechos desde diferentes puntos de vista. Valle-Inclán vuelve a recrear la escena de Baroja, y no el velatorio verdadero de Sawa, porque considera que Baroja no ha tratado dignamente al autor fallecido. Esta intención desterraría la sospecha de plagio, pues Valle-Inclán no copia, sino que quiere que nos demos cuenta de que está contando lo mismo, pero de otra manera; de ahí que mantenga los hitos más importantes, como el asunto de la cerilla ${ }^{21}$. Pero, incluso este despiadado pasaje esconde las divergentes ideas de los dos escritores. Como vimos, a Baroja le refuerza la crítica, mientras que Valle-Inclán lo acepta y lo retoma porque le encaja en la definición de esperpento, es decir, en la deformación grotesca que convierte a los personajes en caricaturas. La cerilla de Baroja es prendida por aquellos que son de la misma calaña que el bohemio muerto, mientras que la de Valle-Inclán atenta contra Max. Por eso, generalizar diciendo «en todo su detalle» es demasiado rotundo. Baroja se posiciona desde las convicciones de Andrés Hurtado o, dicho de otro modo, desde las suyas propias. El gallego,

Nota al pie núm. 104.

No demuestra, en ningún caso, que ocurriese en la realidad. 
por el contrario, no simpatiza con sus personajes, a lo sumo, se compadece de Max, concediéndole el honor de definir el esperpento y retratarle con una marcada superioridad intelectual. Pero Max está creado a partir de. A partir de Alejandro Sawa y lo que Valle-Inclán opinaba de él y a partir de las ideas valleinclanescas respecto a las crisis de Restauración que se sucedieron tras la muerte de Sawa, que son los desencadenantes de la crítica socio-política que encierra Luces de Bohemia. Y su velatorio, a partir del de Villasús, insertando algunos elementos conocidos del de Sawa.

Valle-Inclán no contaría esa escena del modo que lo hace de no ser porque ya lo hizo Baroja. Así, el velatorio de Max Estrella se define por acumulación y contraposición. Contraposición a Baroja y acumulación porque, al estar él allí, aporta datos que sí sucedieron de verdad en el velatorio de Sawa: el clavo que le hirió en la sien a Sawa y la comprobación de la muerte con la ausencia de aliento en un espejo. Pero esto no nos lleva a afirmar que en la raíz del velatorio de Villasús estuviese el del verdadero Sawa. Y, como consecuencia de ello, la realidad que se traslada a la ficción no es tal.

\section{La catalepsia de Sawa de Las máscaras del héroe}

Hasta 1996 hay que avanzar para encontrarse con el último velatorio de Alejandro Sawa. Es curioso que, ya a finales del siglo XX, su figura siga siendo tan atractiva como para volver a aparecer en una novela. Nos estamos refiriendo a Las máscaras del héroe, de Juan Manuel de Prada (1970). Con la Historia como telón de fondo, el autor novela una serie de peripecias de personajes bohemios de principios de siglo, metiéndose en la piel de Pedro Luis de Gálvez ${ }^{22}$, a quien pinta como un joven al que hace testigo de todo aquello que decide contar en primera persona, ocurriendo algo similar a la ficción de El árbol de la ciencia, donde, para Andrés Hurtado, Rafael es únicamente un episodio de su vida. Aquí, Pedro Luis de Gálvez es el protagonista y la muerte de Alejandro Sawa una simple anécdota que presenció en su juventud ${ }^{23}$. Todo ello, sin perder de vista que de Prada busca un premeditado distan-

\footnotetext{
22 (1882-1940), escritor bohemio y malagueño. Juan Manuel de Prada lo convierte en el personaje protagonista.

23 Aquí ocurre algo similar a la aparición de Andrés Hurtado en el velatorio de Villasús porque, al igual que Baroja no estuvo en el entierro de Sawa, Pedro Luis de Gálvez tampoco figuraba en aquella lista de asistentes, convirtiéndose en una mera fachada tras la que esconderse el autor para novelar ciertos acontecimientos de principios de siglo a finales del mismo.
} 
ciamiento de los hechos verídicos para hacer una especie de guiño a ambas obras de principios de siglo que ya hemos tratado.

Alejandro Sawa tan solo aparece en diez de las seiscientas páginas que componen la novela ${ }^{24}$. Quizás, lo que más llama la atención es que no está vivo. Pese a que el lector asiste a los velatorios de Rafael Villasús o Max Estrella, a ambos los conoce en vida (a pesar de que la intervención de Villasús sea breve); sin embargo, al Alejandro Sawa de Las máscaras del héroe se le menciona por primera vez para decir que ha muerto. José Manuel López de Abiada, en su artículo «Imágenes literarias de la bohemia recuperada en la narrativa de Juan Manuel de Prada. Teoría y práctica», repara en que Valle-Inclán y Baroja asisten juntos al entierro:

Una de las escenas más significativas desde el punto de vista narratológico se encuentra en la segunda parte de la novela. Se trata de la escena del velatorio de Alejandro Sawa, al que en la ficción de Prada también asisten dos de los grandes escritores que la habían recogido en sus obras, Pío Baroja y Valle-Inclán (López de Abiada, 2006: 289).

Como ya se puede presuponer, para Las máscaras del héroe es totalmente indiferente que Valle-Inclán asistiese y Baroja no al velatorio real, pues la intención que persigue de Prada es la de hacer ir a dicho velatorio a los dos escritores que ficcionaron el de Sawa. Lo que se crea es un juego con los asistentes en función de la perspectiva que cada novelista quiere dar. A todo lo que ya hemos visto en relación con Max Estrella y Rafael Villasús, hay que sumar la interacción de tres planos, que ya no son simplemente la correlación o no entre ficción y realidad, sino que hay que tener en cuenta a qué escritores de la realidad se elige para novelar y por qué. De este modo, se vuelve a producir en Las máscaras del héroe la acumulación, no solo considerando lo que pudo ser verdad y sazonándolo, sino escribiendo según lo que ya se ha escrito al respecto. Así, Valle-Inclán atiende a lo que dijo Baroja y Juan Manuel de Prada a lo que escribieron ambos noventayochistas. Es más, los dos aparecen como personajes $\mathrm{y}$, como se ha visto antes, sus apariciones representan que son ellos quienes ya han recreado, de algún modo, el velatorio que, por tercera vez, vuelve a la literatura.

24 En la edición que aquí se maneja Prada, (1996: 65-74). 
Retomando la escena, aparece un grupo de bohemios, calificados con adjetivación barojiana, es decir, con desprecio e ironía, que vienen a expresar sus respetos ante el muerto. Entre ellos destaca Ernesto Bark ${ }^{25}$, quien encarna idéntico papel que Basilio Soulinake (y que el desarrapado melenudo sin nombre de El árbol de la ciencia) y repite casi idéntica escena a la de la presunción de catalepsia:

Comenzaron a llegar en riada hombres andrajosos y cabizbajos [...] Encabezaba el grupo un bohemio [...] Ernesto Bark; [...] Ante la pasividad o estupor de los asistentes, se acercó al cadáver de Sawa y, después de aflojarle la mortaja, arrimó la oreja al pecho.

- ¡Está vivo! ¡Aún late su corazón! - gritó como un orate.

- Tal vez nos hallemos ante un caso de catalepsia (Prada, 1996: 69 y ss).

A continuación, de Prada novela el asunto del clavo que perforó la sien de Sawa ya fallecido y que, según Hernández Luquero, fue el causante de la duda sembrada en Valle-Inclán y lo impulsó a hacer la prueba del espejo. Dicha prueba también se recoge en esta novela, pero aquí la hace Emilio Carrère, siendo Valle-Inclán quien aporta sensatez al asunto. Y, de un modo distinto al de quemar los dedos del cadáver con un fósforo como se hace con Max Estrella y Rafael Villasús, pero con idéntica función, aquí se opta por verter cera caliente sobre la herida:

Pidió una vela y probó a verter cera derretida sobre la herida reciente, pero el semblante de Sawa no se contrajo. Carrère propuso hacer la prueba del espejito; [...] Valle se interpuso con esa hidalguía de los muy caballeros [...] (Prada, 1996: 70 y ss).

Por último, Enrique Cornuty aparece como el personaje que se arrodilla ante el cadáver alabando su genio, cumpliendo la función de Don Latino o el viejo borracho: «-¡Amigo queguido! — gangoseaba Cornuty, al estilo gabacho-. ¡Nunca volvegá a habeg un hombre como tú! ¡Nunca! Impúdicamente, cayó de rodillas y empezó a llorar» (Prada, 1996: 70).

25 Juan Manuel de Prada no cambia los nombres por otros inventados, sino que utiliza a los propios escritores que rodeaban a Alejandro Sawa para hacerles personajes que intervienen en el pasaje del velatorio. Ernesto Bark, Enrique Cornuty o Emilio Carrère pertenecían al círculo más íntimo del sevillano. 
Como acabamos de comprobar, el juego de Juan Manuel de Prada es perfecto: no solo desarrolla los acontecimientos en idéntico orden al que aparecen en El árbol de la ciencia y en Luces de Bohemia, sino que, además, reúne las circunstancias que se dieron tanto en la realidad, como en ambas ficciones. Se trata de una suma de elementos que condensan todo lo dicho o escrito a propósito de la muerte del bohemio. Además, dado que lo importante por polémico es el velatorio, no retrata al Sawa vivo adrede. Asimismo, aporta otra ficción más, que es la de hacer ir al entierro a Baroja y Valle-Inclán juntos, cerrando el círculo y haciendo que comprendamos su guiño. Esto lo puede conseguir gracias a un distanciamiento tanto temporal, de unos ochenta años, como del objeto de estudio. La obra de Valle-Inclán está íntimamente ligada a El árbol de la ciencia y no podemos prescindir de su conexión. En cambio, de Prada no perteneció al círculo de Sawa ni su obra se encamina a criticar o remediar algo, de tal modo que se puede permitir tratar a los escritores como personajes y jugar con sus respectivas obras, haciéndoles a ellos partícipes de su propia ficción. Transmutar a todos en personajes le da la oportunidad de llamarles por su nombre para que no quede duda de a quiénes se representaba enmascarados tras seudónimos como el de Villasús o Soulinake. Es más, así no hay distinción entre quiénes eran caracteres y quiénes escritores, pues ahora todos son lo primero.

\section{ERNESTO BARK, CULPABLE}

Aparentemente, todos los personajes principales han quedado identificados, las respectivas comparaciones en cuanto a similitudes y diferencias han sido desarrolladas y hemos trazado la tenue línea que separa realidad y ficción. Asimismo, nos hemos aproximado al estado de la cuestión en lo que a la relación entre las obras se refiere y hemos dado argumentos suficientes para sostener nuestra postura. Sin embargo, una cuestión que parece incongruente ha quedado en el aire: ¿por qué Valle-Inclán, a través del personaje de Basilio Soulinake, hace que Ernesto Bark dude de la efectiva muerte de Max Estrella, cuando Hernández Luquero publicó en 1967 que la incertidumbre con respecto al fallecimiento de Alejandro Sawa la sembró el propio Valle-Inclán? Con el análisis precedente y los datos que vamos a dar a continuación, esperamos dar respuesta a esta pregunta, que constituye el núcleo esencial de esta investigación, pues todo lo anterior se encaminaba 
a desembocar y confluir en este asunto. Parece que el alboroto provocado por la duda sobre el posible estado de catalepsia no admite discusión en tanto que sucedió, pero el periodista Nicasio Hernández Luquero ya nos ha demostrado que la exactitud de datos no es predicable de sus artículos y de ahí que no podamos reconstruir cómo sucedió a partir de sus escritos. Si a esto le añadimos que presenció los hechos siendo muy joven, obnubilado por la figura y las circunstancias de la muerte de Alejandro Sawa, nos vemos obligados a comprobar su relato cotejándolo con otro testimonio. Este es el del propio Ernesto Bark.

Con motivo del fallecimiento del estonio, La Libertad publicó, el 7 de noviembre de 1922, una entrevista que había concedido al periodista Ernesto López-Parra unos meses antes. El fragmento más significativo en cuanto al asunto que estamos tratando es el que sigue:

- ¡Pobre Sawa! - lamentaba Ernesto Bark - . ¡Yo le quería mucho! En París vivimos juntos. Por cierto que el día de su muerte sucedió un caso insólito. Yo no quería que se le enterrase hasta que el cuerpo diese señales de descomposición, porque me inquieta mucho pensar que alguien puede ser enterrado vivo. Tuve que librar una lucha tremenda con los sepultureros, que querían llevárselo a todo trance, en seguida. Luego me enteré que Valle-Inclán había publicado en la revista «España» un artículo contra mí, llamándome espía ruso y afirmando que me había opuesto al entierro de Sawa por no sé qué cosas urdidas por su fantasía. Claro que cuando me encontré a Valle-Inclán en la calle nos pegamos (López-Parra, 1922: 5).

Ernesto Bark reconoce así que fue él mismo el causante del revuelo que se formó al sugerir que Alejandro Sawa no estaba muerto, sino en un estado de catalepsia. Cuando Valle-Inclán recoge el episodio en Luces de Bohemia, ridiculiza la actuación de Basilio Soulinake, cuando Bark tan solo apunta que le inquietaba que lo enterrasen vivo. Pero Bark se reconoció en Basilio y llegó a las manos con el escritor gallego. Obviamente, lo publicado en la revista España no es un artículo contra el estonio, sino una de las entregas semanales de la primera edición de Luces de Bohemia que, como vimos más arriba, se publicó de este modo.

Lo cierto es que Bark, de ser verídicas sus palabras, tenía motivos más que suficientes para dudar de la muerte: «El gran Alejandro Sawa se suicidó con una inyección de morfina, preparada por él, que le aplicó su mujer, sin sa- 
berlo» (López-Parras, 1922: 5). Esto le contaba al periodista que le entrevistó el invierno antes de fallecer. Es más que probable que Sawa recurriese a la morfina, como hacían tantos otros, y más aún para mitigar los dolores provocados por su enfermedad. La pista de que pudo barajar el suicido en algún momento nos la da Valle-Inclán en la misiva que envió a Rubén Darío: «Una locura desesperada. Quería matarse» (Valle-Inclán, 1909). Más allá de estos dos testimonios, no hay ninguna otra prueba que confirme el suicidio del bohemio; aunque sí sabemos, por su reflexión en Iluminaciones en la sombra, que no lo condenaba, sino que lo aprobaba como fin de todos los males y que encontraba en el alcohol y las drogas un modo de mitigar el tormento:

¡Oh alcohol! ¡Oh hastzchiz! ¡Oh santa morfina! [...] Cuando la vida es un tormento, querer dormir - ¡oh dormir! - es el más imperativo de todos los derechos.

¿Y quién, aunque se lo nieguen, no se lo toma por su propia mano? (Sawa, 1977: 130).

Sea como fuere, intencionado o no, el exceso de morfina puede conducir a la catalepsia. Esto es debido a que la morfina es un derivado del opio y todos los opiáceos, en sobredosis, llevan a un descenso de las constantes vitales, lo que puede desembocar en una aparente muerte, conocida como catalepsia. Si Ernesto Bark conocía estos efectos, la opinión de su amigo para con la morfina, que había insinuado que quería matarse y que su mujer le administraba las inyecciones para paliar los dolores, sus temores para dudar de la muerte de Sawa estaban más que justificados.

\section{CONCLUSIONES}

Queda demostrado que fue Bark, y no Valle-Inclán, quien desencadenó el asunto de la catalepsia que tanta recreación ha dado en la ficción (si bien de un modo más impresionista que realista). Lo que no sabemos, de momento, es si el sevillano contó explícitamente al estonio sus intenciones de acabar con su propia vida a través de la inyección de morfina.

Debemos recalcar que los tres pasajes de las obras que hemos tratado no funcionan de manera independiente, sino de forma acumulativa, contribuyendo a la distorsión de la verdadera muerte de Alejandro Sawa, quien ha 
quedado reducido a este tipo de anécdotas. El velatorio de Max Estrella se desarrolla a partir del velatorio de Villasús cambiando la perspectiva, detallándose más y poniendo nombre a todos los personajes, pero teniendo como elementos principales el supuesto estado de catalepsia, la comprobación de la muerte quemando los dedos del cadáver con un fósforo y la intervención de un personaje que se arrodilla alabando al fallecido y lamentándose casi con idénticas palabras. Por su parte, el velatorio del Sawa de Las máscaras del héroe, tal y como apreciaba López de Abiada, se construye haciendo ir al mismo a los dos autores que ya lo recrearon en sus obras. Es más, como hemos visto, se vuelve a repetir la misma escena, ahora con nombres reales, retomándose la duda de la muerte y vertiendo cera en los dedos para comprobar la defunción. En este caso, el viejo borracho de melenas equivalente a Don Latino es sustituido por Enrique Cornuty, dado que este era un inseparable amigo de Sawa. Todos estos detalles que se van acumulando no parten de una intención de veracidad, sino de unos escasos datos conocidos que Baroja distorsionó y completó con imaginación y prejuicios. Valle-Inclán aporta la anécdota del clavo y la comprobación del espejo y de Prada opta por reunir todo y a todos. De este modo, lejos de buscar la exactitud, los detalles se fijan en las obras con razón de ser porque se sujetan a las intenciones de cada autor y a ciertos acontecimientos sobre los que elaborar la ficción.

Pese a todo, el reiterado supuesto de catalepsia tiene razón de ser en relación con su correspondencia con la realidad, y responde perfectamente al propósito de cada escritor: para Baroja el personaje que siembra la duda es totalmente irrelevante, pues se trata de un bohemio más, amigo del fallecido. En el hipotético caso de que el vasco, pese a no asistir al velatorio, tuviese constancia de que el alboroto venía de Bark, este seguiría siendo un bohemio más, amigo de Sawa, sin mayor relevancia. Además, ¿para qué iba a poner nombre a un personaje más en El árbol de la ciencia, si ya de por sí Villasús es secundario y lo trata despectivamente? En cambio, en Luces de Bohemia cobra sentido, pues la escena cumbre es la muerte de Max Estrella. Es más, al estar presente Valle-Inclán en el velatorio real de Sawa, sabía de la intervención de Bark y, a su vez, Bark se reconoce en Basilio y se lo toma como una burla u ofensa. El hecho de que Valle-Inclán nunca negase esta correspondencia entre persona y personaje, junto con las confesiones de Bark reconociendo su preocupación y lucha con los sepultureros, nos ayuda a comprender mejor Luces de Bohemia y nos hace desterrar el testimonio de Luquero sobre las fan- 
tasías valleinclanescas. Con respecto a la novela de Juan Manuel de Prada, no nos ha de sorprender que el autor llame al personaje con su nombre y apellidos, pues, como decíamos, existe un distanciamiento y una intencionalidad. El Sawa vivo no le interesa a de Prada. Sin embargo, conocía sobradamente la tradicional identificación de Basilio Soulinake con Ernesto Bark y la pelea que libró con el gallego por reconocerse a sí mismo, así como la relación entre El árbol de la ciencia y Luces de Bohemia.

\section{REFERENCIAS BIBLIOGRÁFICAS}

(1909), «Entierro de Alejandro Sawa», en El País. Diario republicano (18871921), 5 de marzo.

(1922), «Ernesto Bark», en La Acción, 25 de octubre

Baroja, Pío (2005), El árbol de la ciencia, ed. de Pío Caro Baroja, Madrid, Cátedra.

Caro Baroja, Pío (2005), «Introducción» a Pío Baroja, El árbol de la ciencia, Madrid, Cátedra, págs. 11-28.

Correa Ramón, Amelina (1993), Alejandro Sawa y el Naturalismo Literario, Granada, Universidad de Granada.

Correa Ramón, Amelina (2008), Alejandro Sawa, Luces de bohemia, Sevilla, Fundación José Manuel Lara.

Ena BordonAdA, Angela (2012-2013), «Revisitando Iluminaciones en la sombra de Alejandro Sawa», Journal of Hispanic Modernism, núm. 3-4, pp. 39-58.

García Besada, Alberto (2001), «La muerte de Alejandro Sawa en "Luces de bohemia" y "El árbol de la ciencia"», Aljamía. Revista de la Consejería de Educación y Ciencia en Marruecos, núm. 13, pp. 59-65.

GonZÁlez Martel, Juan Manuel (2006), «La amistad de Alejandro Sawa y Ramón del Valle Inclán en el Archivo de los Sawa (1862-1984)», Madrygal, núm.9, pp. 73-84, http://revistas.ucm.es/fll/11389664/articulos/MADR0606110073A.PDF (23-11-2016). 
Hernández Luquero, Nicasio (1909), «Alejandro Sawa, muerto», en El País. Diario republicano (1887-1921), 8 de marzo.

Hernández Luquero, Nicasio (1967), «Recuerdo literario, Alejandro Sawa», en El Diario de Ávila, 2 de mayo.

Hernández Luquero, Nicasio (1974), «Alejandro Sawa, un olvidado», en $A B C, 22$ de mayo.

Iglesias Hermida, Prudencio (1909), De mi museo, Madrid, Imprenta Ibérica.

LóPeZ DE ABIADA, José Manuel (2006), «Imágenes literarias de la bohemia recuperada en la narrativa de Juan Manuel de Prada. Teoría y práctica», en Antonio Cruz Casado (ed.), Bohemios, raros y olvidados, Córdoba, Diputación Provincial / Ayuntamiento de Lucena, pp. 265-306, http://www. cervantesvirtual.com/obra/imgenes-literarias-de-la-bohemia-recuperada-en-la-narrativa-de-jm-de-prada-0/ (23-11-2016).

López-PARRA, Ernesto (1922), «Ernesto Bark y la Casa de la Bohemia», en La Libertad, 7 de noviembre.

LóPEZ-PARRA, Ernesto (1927), «Recuerdos de la pintoresca bohemia literaria de Madrid», en El Heraldo de Madrid, 26 de abril.

PhilliPs, Allen (1976), Alejandro Sawa. Mito y realidad, Madrid, Turner.

PRADA, Juan Manuel de (1996), Las máscaras del héroe, Madrid, Valdemar.

SAWA, Alejandro (1977), Iluminaciones en la sombra, ed., estudio y notas de Iris Zavala, Madrid, Alhambra.

Valle-Inclán, Ramón (1987), Luces de Bohemia. ed. de Alonso Zamora Vicente, Madrid, Espasa-Calpe.

Valle-Inclán, Ramón (3 de marzo de 1909), Carta a Rubén Darío. Archivo Rubén Darío, Universidad Complutense de Madrid, doc. 2036, http://alfama.sim.ucm.es/greco/rd-digital.php?search=2036 (23-11-2016).

Zamora Vicente, Alonso (1967), Asedio a Luces de Bohemia, primer esperpento de Ramón del Valle-Inclán, Madrid, Real Academia Española, http:/ / www. cervantesvirtual.com/obra-visor/asedio-a-luces-de-bohemia-primer-esperpento-de-ramn-del-valle-incln-0/html/ (23-11-2016). 


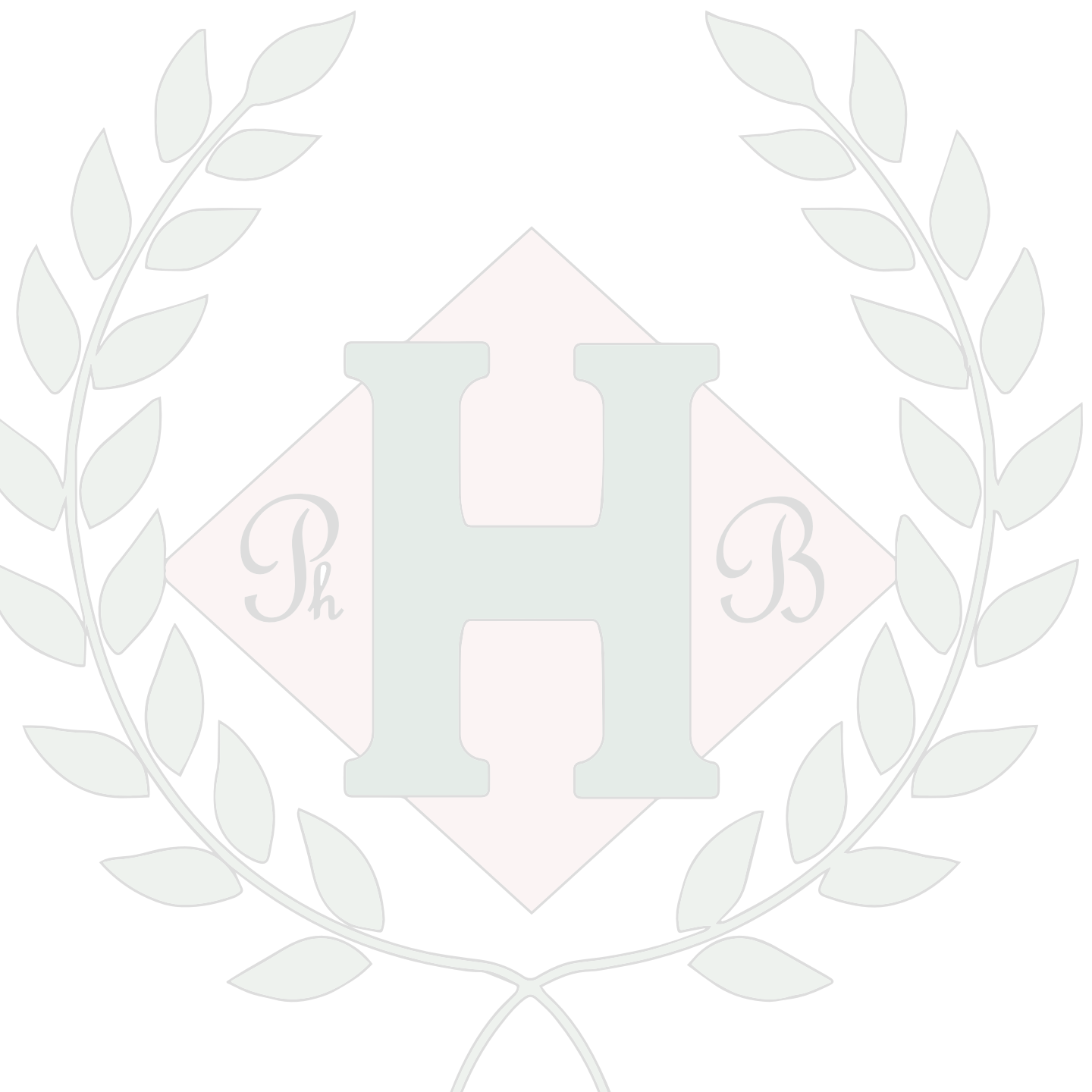

